quality of healthcare that my patients deserved. These corporate dental companies appear to have tapped into the vast 'pool' of overseas dentists, the majority of whom unfortunately are not familiar with NHS, GDC and NICE guidelines. Most patients who spoke to me complained that they were not happy with the service and treatment that they had received from their dentist and as a result left the practice. This happened almost on a daily basis. In my opinion, corporate dental companies are ruining both the reputation and business of dentistry in the UK.

I am currently working one and a half days a week as a dental therapist. Apart from the same corporate dental company, there are no employers locally advertising for dental hygienist-therapists. After typing this letter, next on my 'to do' list is to fill out an application form for the local supermarket to try and fill the rest of my week so I can keep the roof over my head and support family.

\section{H. Griffiths}

By email

DOI: 10.1038/sj.bdj.2010.214

\section{IOM AWARENESS}

Sir, I should like to share with your readers the efforts of Dentaid, the oral health charity, to promote its 'Action against Infant Oral Mutilation' (IOM). Village healers usually carry out this traditional practice, prevalent in DR Congo, Ethiopia, Kenya, Somalia, Sudan, Tanzania and Uganda.

If an infant is suffering from diarrhoea, vomiting or fevers, the healer will tell the mother that the child has "tooth worms' which must be removed or the child may die. These 'tooth worms' are the unerupted tooth buds, usually of the lower canines, which then are prised out of the gum using unsterile tools such as a bicycle spoke, a nail or knife, without anaesthesia.

The resulting blood loss and shock can lead to anaemia; the unhygienic methods can cause septicaemia, tetanus and/or HIV/AIDS and can on occasions be fatal. Long-term effects can include eradication and/or malformation of other primary and permanent teeth in the area.

Dentaid has formed an Action Group to formulate strategies to address this practice and an Information Leaflet has been produced to raise awareness of IOM amongst governments, dental schools, health professionals, teachers and charity workers in Africa and in countries such as the UK in which immigrants settle.

Further information about IOM can be obtained from www.dentaid.org (click on Overseas Projects) and the Information Leaflet may be downloaded as a PDF file.

If any of your readers have connections with charities or health personnel working in these countries and would like copies of this leaflet to pass on to them, these are available free of charge from Dentaid. Please email me at rosemary@dentaid.org with your details and the quantity required.

R. Longhurst Exmouth

Dentaid Action Group Member DOI: 10.1038/sj.bdj.2010.215

\section{PAPER CLIP IMPLANT}

Sir, I thought the attached radiograph might be of some interest to the wider profession. The 'paper clip' design implant was placed with a 'hammer and chisel' (patient's description!) when the patient was 18 , now 48 . The conventional implant was placed three years ago. Both are rock solid.

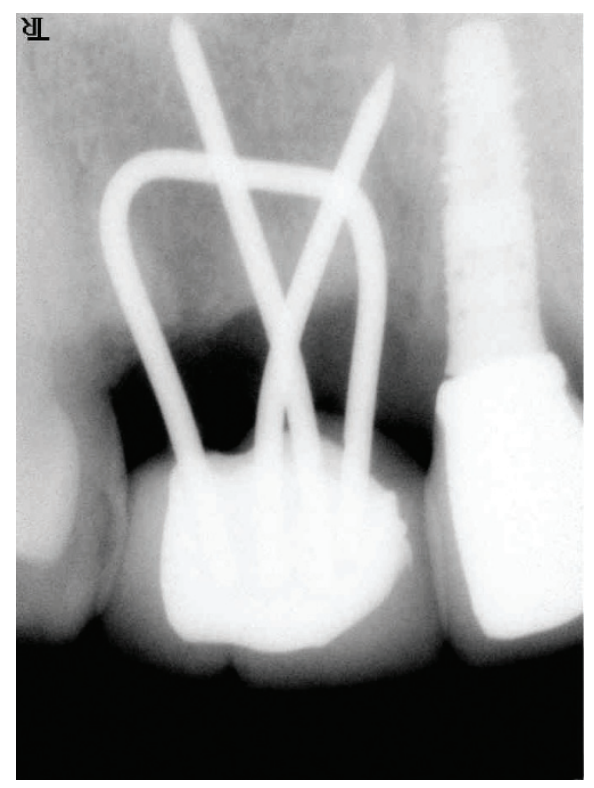

Fig. 1 Implants old and new

S. Bazlinton By email DOI: 10.1038/sj.bdj.2010.216 